\title{
Acceptatie van de Persoonlijke Gezondheidscheck in vier Brabantse gemeenten. Wat levert dit e-healthinstrument op?
}

\author{
Lieke Raaijmakers · Marieke Rombouts · Tim de Vuijst · Theo Kuunders · len van de Goor
}

Published online: 19 February 2019

(C) The Author(s) 2019

\begin{abstract}
Samenvatting De Persoonlijke Gezondheidscheck is een wetenschappelijk onderbouwd e-healthinstrument voor persoonlijk gezondheidsmanagement. De PGC is in 2016 geïmplementeerd in vier Brabantse gemeenten. Van de 21.735 genodigden heeft $12 \%$ ( $n=2732)$ deelgenomen. Dit onderzoek was gericht op de mate van acceptatie van de PGC bij cliënten en professionals in de eerstelijnsgezondheidszorg. Deelnemers en professionals zijn overwegend positief over (het gebruik van) de PGC. Deelnemers geven aan (pogingen te doen) de leefstijladviezen op te volgen. Een uitnodiging van de huisarts lijkt de respons te verdubbelen, vergeleken met een uitnodiging door de gemeente. De overall lage respons maakt het gebruik van de PGC-resultaten voor lokaal gezondheidsbeleid nog niet mogelijk.
\end{abstract}

Vergrijzing en een toenemende last van chronische ziekten worden op dit moment beschouwd als grote maatschappelijke en economische uitdagingen in de publieke gezondheid. Vooral voor leefstijlgerelateerde chronische aandoeningen is het van belang dat er goede instrumenten zijn om leefstijl en gezondheid te monitoren, waardoor gezondheidsrisico's in een vroeg stadium kunnen worden opgespoord. Daarnaast is het van groot belang om interventies te ontwikkelen die het zelfmanagement van de burger kunnen bevor-

Dr. L. Raaijmakers $(\bowtie) \cdot M$. Rombouts

GGD West-Brabant, Breda, Nederland

1.raaijmakers@ggdwestbrabant.nl

T. de Vuijst · dr. T. Kuunders

GGD Hart voor Brabant, 's-Hertogenbosch, Nederland

prof.dr. I. van de Goor

Afdeling Tranzo, Tilburg School of Social and Behavioral

Sciences, Tilburg University, Tilburg, Nederland deren. Wanneer dergelijke interventies succesvol op grote schaal worden geïmplementeerd, is het aannemelijk dat burgers minder gebruik zullen maken van de gezondheidszorg $[1,2]$.

Steeds vaker worden e-healthtoepassingen ingezet bij gezondheidsbevordering in de eerstelijnszorg. Een van deze toepassingen is de Persoonlijke Gezondheidscheck. Dit project richtte zich op het verkrijgen van inzicht in de mate van acceptatie van de Persoonlijke Gezondheidscheck (PGC) en de leefstijladviezen die het genereert door deelnemers en professionals in de eerstelijnsgezondheidszorg, alsook op de bruikbaarheid van de PGC-data voor de ontwikkeling van lokaal gezondheidsbeleid.

\section{De Persoonlijke Gezondheidscheck}

De PGC, ontwikkeld door het Netherlands Institute for Prevention and E-health Development (NIPED), is een onderbouwd e-healthinstrument voor persoonlijk gezondheidsmanagement [3]. De PGC beoogt deelnemers meer inzicht in hun gezondheid en leefstijl te geven, bewust te maken en aan te zetten tot actie. Voor dit onderzoek is gekozen om met de online PGC-vragenlijst de gezondheid en risicofactoren van bewoners in kaart te brengen. Indien de vragenlijst een verhoogd risico op gezondheidsproblemen aantoonde, kon er aanvullend onderzoek verricht worden bij een checkpoint, bemand door de GGD in een huisartsenpraktijk of buurthuis. Bij dit checkpoint werden de bloeddruk en hartslag gemeten, en werd via een vingerprik bloed afgenomen om HbAlc en cholesterol te bepalen. De bevindingen resulteerden in een individueel gezondheidsrapport met praktische adviezen op maat voor een gezondere leefstijl. 


\section{Uitvoering van de PGC en evaluatie}

De PGC is aangeboden aan een deel van de inwoners van de vier Brabantse gemeenten Goirle, Oisterwijk, Oosterhout en Uden op een manier die het beste paste bij de lokale omstandigheden. De wervingsstrategieën en het aantal genodigden verschilden daardoor per gemeente. In de gemeente Goirle zijn 4.138 bewoners per brief uitgenodigd door hun huisartsenpraktijk. De gemeente Oisterwijk heeft 2.300 bewoners van één wijk per brief, ondertekend door de GGD, uitgenodigd. In de gemeente Oosterhout zijn 10.000 bewoners van één wijk per brief uitgenodigd door de gemeente. De gemeente Uden heeft 5.297 bewoners eveneens uit één wijk binnen de gemeente per brief uitgenodigd. In Uden is de herinneringsbrief gezamenlijk door de gemeente, huisartsen en GGD Hart voor Brabant ondertekend. De genodigden in Oisterwijk waren 18 jaar en ouder, die uit de overige gemeenten waren 25 jaar en ouder.

Het onderzoek naar de acceptatie van het instrument (september 2016 tot februari 2018) had een observationeel ontwerp; de onderzoekers hebben geen invloed gehad op het wervingsproces. De acceptatie van de PGC is onderzocht met de Unified Theory of Acceptance and Use of Technology (UTAUT) [4]. Dit model wordt breed toegepast om de acceptatie, implementatie en (intentie tot) het gebruik van nieuwe technologieën te onderzoeken. Het model gaat uit van vier hoofdconstructen: prestatieverwachting, inspanningsverwachting, sociale invloed en faciliterende omstandigheden. In dit onderzoek zijn de volgende onderzoeksmethoden toegepast: (geanonimiseerde) gegevens uit de PGC, follow-upvragenlijsten voor alle PGC-deelnemers 5 dagen $(n=684)$, 3 maanden $(n=367)$ en 6 maanden $(n=441)$ na deelname, focusgroepen met PGC-deelnemers $(n=25)$ en eerstelijnsprofessionals $(n=12)$ en telefonische interviews met niet-deelnemers $(n=58)$.

\section{Respons}

In totaal zijn 21.735 mensen uitgenodigd voor deelname aan de PGC. De totale respons was $12 \%(2.732$ deelnemers). Er waren echter grote verschillen in respons tussen de vier gemeenten: Goirle $22 \%(n=898)$, Oisterwijk 12\% ( $n=276)$, Oosterhout 10\% $(n=954)$ en Uden $10 \%$ ( $n=537)$. De totale respons op de 5-dagen-, 3-maanden- en 6-maandenvragenlijst verschilde ook met respectievelijk 26\% ( $n=684), 14 \%$ ( $n=367)$ en $17 \%$ $(n=441)$. Deelname was anoniem, waardoor de vragenlijsten niet aan een persoon te koppelen waren.

\section{Resultaten}

\section{Achtergrondkenmerken en gezondheid van} deelnemers op basis van de PGC-vragenlijst

Tab. 1 toont de achtergrondkenmerken en het leefstijlprofiel van deelnemers. Er zijn iets meer vrouwen, de gemiddelde leeftijd is 54 jaar en het merendeel is middel of hoger opgeleid. Het overall leefstijlprofiel is bovengemiddeld gezond als we kijken naar landelijke en gemeentelijke cijfers (weinig rokers, de meerderheid beweegt voldoende en ontbijt regelmatig, maar twee derde drinkt boven de norm en eet onvoldoende groente en fruit) [5]. Van degenen met aanvullend labonderzoek $(n=668)$ heeft $64 \%$ een verhoogd risico op een cardiovasculaire aandoening [6]. Van de deelnemers van wie geen labwaarden bekend zijn ( $n=2.001)$ heeft $89 \%$ een verhoogd risico op een of meer cardiometabole aandoeningen [7].

\section{Acceptatie van de PGC en de leefstijladviezen door deelnemers}

Meer dan de helft van de deelnemers (63\%) had vijf dagen na deelname aan de PGC een positieve verwachting van de bijdrage die het instrument kan leveren aan hun gezondheid. Uit de groepsinterviews kwam naar voren dat deelnemers dachten dat het bewustzijn zou creëren en ze hoopten op een bevestiging van hun naar eigen zeggen gezonde gedrag. De deelnemers waren positief over het initiatief van de gemeenten om de PGC onder de burgers te implementeren en de meerderheid vond het instrument gebruiksvriendelijk, logisch en begrijpelijk. Toch sluiten de antwoordmogelijkheden en de resultaten van de PGC niet altijd aan bij de persoonlijke situatie van de deelnemers. In sommige gevallen hadden ze het gevoel dat ze niet altijd het gewenste antwoord konden geven, waardoor het gezondheidsrapport en bijbehorende adviezen niet volledig aansloten. De meeste deelnemers gaven aan te beschikken over de kennis, middelen (zoals computer, wifi en internet) en ondersteuning die noodzakelijk zijn om gebruik te maken van de PGC. Ongeveer twee derde gaf aan dat zij vanuit hun omgeving niet gestimuleerd werden om de PGC te gebruiken en er is in hun omgeving slechts beperkt over de PGC gesproken. Ruim de helft van de deelnemers $(57 \%)$ was niet bereid om voor de PGC te betalen, omdat ze vonden dat de zorgverzekering dit zou moeten vergoeden of omdat ze de toegevoegde waarde van de PGC niet inzagen. Dat daargelaten gaf de helft na deelname aan meer gemotiveerd te zijn om de gezondheid te verbeteren. De helft van de deelnemers met een suboptimale leefstijl wilde na zes maanden nog steeds actie ondernemen om de gezondheid te verbeteren. De meeste deelnemers die na zes maanden nog actie ondernamen om hun gezondheid te verbeteren op het gebied van alcoholgebruik (97\%), eetgedrag (91\%) en mentale klachten (89\%) de- 
Tabel 1 Achtergrondkenmerken en gezondheid van deelnemers op basis van de PGC-vragenlijst

\begin{tabular}{|c|c|c|}
\hline \multicolumn{3}{|c|}{ Geslacht (\%) } \\
\hline & - Man & 44 \\
\hline & Vrouw & 56 \\
\hline & emiddelde leeftijd & $54(s d 13,7)$ \\
\hline \multicolumn{3}{|c|}{ Opleidingsniveau (\%) } \\
\hline & Laag & 23 \\
\hline & Midden & 39 \\
\hline & Hoog & 38 \\
\hline \multicolumn{3}{|c|}{ Body mass index (\%) } \\
\hline & Ondergewicht $(<18,5)$ & 1 \\
\hline & Normaal gewicht (18,5-25) & 49 \\
\hline & - Overgewicht (25-30) & 38 \\
\hline & Obesitas ( $\geq 30$ ) & 12 \\
\hline \multicolumn{3}{|c|}{ Roken (\%) } \\
\hline & Ja & 15 \\
\hline & Nee & 85 \\
\hline \multicolumn{3}{|c|}{ Eetgedrag (\%) } \\
\hline & $\begin{array}{l}\text { Voldoet aan de norm voor groente consumptie }(200 \mathrm{~g} \\
\text { per dag) }\end{array}$ & 18 \\
\hline & $\begin{array}{l}\text { Voldoet aan de norm voor fruit consumptie (2 stuks per } \\
\text { dag) }\end{array}$ & 35 \\
\hline & Ontbijt dagelijks & 82 \\
\hline & Eet $\geq 1$ keer per week vis & 62 \\
\hline \multicolumn{3}{|c|}{ Bewegen (\%) } \\
\hline & $\begin{array}{l}\text { Voldoet aan de Nederlandse Norm Gezond Bewegen } \\
\text { (minimaal } 150 \text { minuten matig intensieve inspanning } \\
\text { per week) }\end{array}$ & 74 \\
\hline \multicolumn{3}{|c|}{ Alcoholinname (\%) } \\
\hline & Drinkt minder dan 7 glazen alcohol per week & 70 \\
\hline \multicolumn{3}{|c|}{ Gezondheidsrisico's (\%) } \\
\hline & Verhoogd risico op een cardiovasculaire aandoening & 64 \\
\hline & - Verhoogd risico op een cardiometabole aandoening & 89 \\
\hline
\end{tabular}

den dit individueel. Beweeggedrag werd daarnaast het vaakst in groepsverband opgepakt en fysieke klachten werden het meest samen met een professional aangepakt. We kunnen echter niet uitsluiten dat de gerapporteerde (motivatie tot) acties ook zou zijn opgetreden zonder deelname aan de PGC, aangezien in dit onderzoek geen controlegroep aanwezig is.

\section{Acceptatie van de PGC door (eerstelijnszorg)professionals}

Uit de groepsinterviews blijkt dat (eerstelijnszorg) professionals in de pilotgemeenten overwegend positief zijn over de insteek van de PGC en denken dat het instrument een meerwaarde heeft voor het bevorderen van de volksgezondheid. Ze waren van mening dat e-healthtoepassingen goed aansluiten bij de huidige tijd en drempelverlagend kunnen werken. De deelnemende professionals denken wel dat het instrument (nog) niet voor iedereen geschikt is en vinden de PGC-vragenlijst erg uitgebreid. Daarom doen zij de suggestie om een 'light-versie' te ontwikkelen, zodat mogelijk ook mensen met een lagere opleiding eerder bereid zijn deel te nemen. Professionals adviseren om de kosten van de PGC voor de deelnemers zo laag mogelijk te houden. Hoge kosten zouden volgens hen leiden tot een zeer selecte groep deelnemers.

Huisartsen hadden de verwachting dat de PGC tot een grote toeloop van deelnemers naar de huisartsenpraktijken zou leiden. Ze hadden veel deelnemers met vragen of zorgen en daarmee een tijdelijke toename in werkdruk verwacht. Dit effect is echter uitgebleven. Huisartsen hebben in alle gemeenten slechts een handjevol patiënten op het spreekuur gehad naar aanleiding van deelname aan de PGC. Ze vragen zich dan ook af of de PGC wel de mensen bereikt bij wie de meeste gezondheidswinst te behalen is. Kijkend naar het leefstijlprofiel van de deelnemers, dat aan de bovenkant van de gemiddelden ligt vergeleken met gemeentelijke en landelijke cijfers, lijkt dit niet het geval [5]. Huisartsen beschouwden de PGC als een mooie aanvulling op de beperkte tijd die er tijdens een consult voor preventie is. Wel hadden ze graag de mogelijkheid gehad om de PGC-data van hun patiënten in te zien om meer te weten te komen over de patiënten die ze nooit op het spreekuur zien. Dit blijkt wel mogelijk te zijn via een portal voor professionals, mits een deelnemer toestemming geeft.

\section{Redenen om niet deel te nemen aan de PGC}

De voornaamste reden die genodigden tijdens de telefonische interviews noemden om niet deel te nemen aan de PGC, is dat zij al onder controle van de huisarts en/of specialist in het ziekenhuis staan. Daarnaast waren er al relatief veel genodigden die jaarlijks bij de huisarts of via de werkgever een gezondheidscheck lieten uitvoeren. Tevens gaven genodigden aan dat ze vanwege privacygerelateerde redenen niet wilden deelnemen. Ze willen vertrouwelijke gezondheidsinformatie alléén delen met de huisarts.

\section{Inzet van de PGC-data als onderbouwing voor lo- kaal gezondheidsbeleid}

In dit pilotonderzoek is ook nagegaan of de data van de PGC bruikbaar waren voor het onderbouwen van lokaal gezondheidsbeleid. Vanwege de lagere respons op de PGC (gemiddeld 12\%) in vergelijking met de respons op de Gezondheidsmonitoren van de GGD, respectievelijk $28-33 \%$ voor volwassenen en $48-50 \%$ voor ouderen in de GGD-regio's Hart voor Brabant en West-Brabant [8], lijkt dit nog niet aan te bevelen met de huidige implementatiemethodiek. De kans op selectiviteit van de respons is daarmee sterk aanwezig. Wanneer we de (achtergrond)kenmerken van de deelnemers in deze pilot vergelijken met die van de landelijke en gemeentelijke populaties, kunnen we stellen dat laagopgeleiden, jongeren en mensen met een on- 
Tabel 2 Aanbevelingen voor het implementatieproces van de PGC

\begin{tabular}{|c|c|}
\hline Thema & Aanbevelingen \\
\hline \multirow[t]{3}{*}{ Wijze van uitnodigen } & $\begin{array}{l}\text { Denk goed na over de wijze waarop potentiële deelnemers worden uitgenodigd. Naast het uitnodigen via een } \\
\text { huisartsenpraktijk zouden er nog andere geschikte kanalen kunnen zijn om deelnemers te werven }\end{array}$ \\
\hline & Maak bij het uitnodigen gebruik van (cultureel) aangepast materiaal [11] \\
\hline & $\begin{array}{l}\text { Met ingang van } 2019 \text { wordt leefstijlcoaching voor mensen met een medische indicatie vergoed uit de basisverzeke- } \\
\text { ring [12]. Dit kan een activerende rol spelen bij de werving voor deelname aan de PGC, bijvoorbeeld bij samenwer- } \\
\text { king met de huisartsenpraktijk }\end{array}$ \\
\hline Responsverhogende maatregelen & $\begin{array}{l}\text { Overweeg de volgende responsverhogende maatregelen bij toekomstige implementaties van de PGC: het verhogen } \\
\text { van het aantal en soort contactpogingen met de doelgroep en het hanteren van een benaderingsstrategie voor } \\
\text { groepen die ondervertegenwoordigd zijn in de respons (zie de handreiking voor gemeenten voor een uitgebreide } \\
\text { weergave van de maatregelen) }[11,13]\end{array}$ \\
\hline Inzicht voor artsen in PGC-data & $\begin{array}{l}\text { Voor huisartsen zou (met toestemming van patiënten) een groter inzicht in de gezondheid van patiënten die zelden } \\
\text { op het spreekuur komen een grote meerwaarde bieden, om zo consulttijd efficiënter aan preventie te besteden. } \\
\text { Hiermee kan het draagvlak voor de PGC vergroot worden en invloed uitgeoefend worden op de respons van deelne- } \\
\text { mers }\end{array}$ \\
\hline Kosten voor deelname & $\begin{array}{l}\text { Houdt de eigen bijdrage voor deelname zo laag mogelijk. Dit wordt nu al deels bereikt doordat meerdere zorgverze- } \\
\text { keraars de PGC in hun verzekeringen hebben opgenomen. Bovendien wordt leefstijlcoaching met ingang van } 2019 \\
\text { vergoed uit de basisverzekering voor mensen met een medische indicatie [12] }\end{array}$ \\
\hline Adequate opvolging voor PGC-deelnemers & $\begin{array}{l}\text { Adequate begeleiding in de uitvoerings- en consolidatiefase van gedragsverandering als gevolg van deelname is } \\
\text { noodzakelijk (bijvoorbeeld door aansluiting bij een gecombineerde leefstijlinterventie) }\end{array}$ \\
\hline \multirow[t]{2}{*}{ Aanpassing van het instrument } & $\begin{array}{l}\text { De PGC kan beter worden afgestemd op de persoonlijke situatie van deelnemers door vragen en antwoordcatego- } \\
\text { rieën toe te voegen en adviezen beter aan te laten sluiten. Het is aan te raden de doelgroep hierbij te betrekken }\end{array}$ \\
\hline & $\begin{array}{l}\text { Houd rekening met het feit dat niet iedereen voldoende kennis heeft van gezond gedrag of moeite heeft met het be- } \\
\text { grijpen van gezondheidsinformatie [14]. Het NIPED werkt daarom in het kader van de Health Deal 'Stimulering ge- } \\
\text { zondheid door persoonlijke preventie via e-health' aan het vereenvoudigen van de PGC, zodat deze in de toekomst } \\
\text { toegankelijker wordt voor alle Nederlanders. De PGC is inmiddels in zijn geheel beschikbaar voor laaggeletterden }\end{array}$ \\
\hline
\end{tabular}

gezonde leefstijl in deze pilot ondervertegenwoordigd zijn $[5,8,9]$.

\section{Conclusie}

De respons op de uitnodiging om deel te nemen aan de PGC is in vergelijking met de respons op de Gezondheidsmonitoren van de GGD substantieel lager. De respons lijkt te verdubbelen wanneer de huisarts de uitnodiging voor deelname ondertekent, wat daardoor een belangrijke succesfactor is voor een beter bereik van de doelgroep. Dit komt overeen met ander onderzoek naar bijvoorbeeld de motivatie voor deelname aan de griepprik [10]. Tegelijkertijd blijken laagopgeleiden, jongeren en mensen met een ongezonde leefstijl ondervertegenwoordigd te zijn. Het lijkt erop dat de wijze waarop de PGC in 2016 in de pilotgemeenten is aangeboden en het instrument zelf nog onvoldoende toereikend waren om deze groepen te bereiken. Dit wordt bevestigd door de interviews met professionals en deelnemers. Samen met de lage respons maakt dit de resultaten van de PGC-vragenlijst niet representatief voor de wijken en huisartsenpopulaties waar de deelnemers geworven zijn. Daarom kunnen de PGC-data op basis van deze pilot geen geschikte input leveren voor het ontwikkelen van lokaal gezondheidsbeleid.

De resultaten laten zien dat professionals en deelnemers in deze pilot overwegend positief zijn over de PGC als e-healthinstrument. Vrijwel alle deelnemers beschikken over de kennis, middelen en ondersteuning die nodig zijn om gebruik te maken van de PGC.
De rol van de sociale omgeving bij het gebruik van de PGC, zoals vrienden, familie en de eerstelijnszorg, lijkt beperkt. Een meerderheid van de deelnemers geeft aan dat ze vanuit hun omgeving niet gestimuleerd worden om de PGC te gebruiken en er is in hun omgeving tijdens de pilot slechts beperkt over de PGC gesproken. De PGC lijkt een grote groep van de deelnemers aan te zetten tot meer bewustzijn en actie om de gezondheid te verbeteren. Het is echter niet bekend hoe zij dit aanpakken en of het gewenste effect wordt bereikt. Toeleiding naar de PGC is een noodzakelijke eerste stap om uiteindelijk tot de gewenste gedragsverandering te komen, waarbij het erop lijkt dat een uitnodiging vanuit de huisartsenpraktijk hiervoor een betere uitgangssituatie geeft. De response rates voor ons onderzoek waren relatief laag, dus verhoging van de respons vergt specifieke aandacht. Bij een onderzoek werd voor de voorloper van de PGC (het Preventieconsult) een response rate bereikt van $70 \%$, van wie $62 \%$ de (papieren) risicotest daadwerkelijk invulde [11]. Hierbij werd gebruikgemaakt van uitnodigingsstrategieën en materialen die aangepast waren voor groepen met een lage SES en diverse groepen met een niet-westerse achtergrond. Naast de schriftelijke uitnodiging van de huisarts bleek vooral een telefonische reminder door de praktijkassistente een belangrijke responsverhogende factor [11]. Wanneer de resultaten op het gebied van gedragsverandering hetzelfde zouden zijn met een hogere respons, kan de PGC een veelbelovend e-healthinstrument zijn, dat goed aansluit bij de behoeften van de huidige maatschappij. Een daadkrachtige aanpak om deelnemers 
aan de PGC te ondersteunen bij het verbeteren van hun gezondheid en leefstijl is echter van belang om duurzame gedragsverandering te bereiken. Hierbij is het belangrijk dat een deelnemer zich kan herkennen in het ongewenste gedrag en de manier waarop dit veranderd kan worden. Er is vanuit de deelnemers behoefte aan een betere aansluiting bij de persoonlijke situatie als het gaat om de PGC-vragenlijst en het gezondheidsrapport en -adviezen. Anders dan tijdens ons onderzoek het geval was is de PGC inmiddels in zijn geheel beschikbaar voor laaggeletterden.

\section{Aanbevelingen}

Tab. 2 geeft een overzicht van de belangrijkste aanbevelingen voor het implementatieproces van de PGC die zijn geformuleerd op basis van de resultaten van dit onderzoek.

Open Access This article is distributed under the terms of the Creative Commons Attribution 4.0 International License (http://creativecommons.org/licenses/by/4.0/), which permits unrestricted use, distribution, and reproduction in any medium, provided you give appropriate credit to the original author(s) and the source, provide a link to the Creative Commons license, and indicate if changes were made.

\section{Literatuur}

1. Baardman J, Booys Mde, Meulmeester M. Overzelfmanagement van de patiënt en wat eHealth daaraan kan bijdragen. Zelfmanagement 2.0. Utrecht: Nederlandse Patiënten Consumenten Federatie; 2009.

2. Verwey R, Hochstenbach L, Vermeulen J, et al. Technologie ondersteunt patiënt bij zelfmanagement. Tijdschr Verpleegkd. 2013;6:14-7.

3. NIPED. Wat is de gezondheidscheck. Amsterdam: NIPED. 2018. https://www.persoonlijkegezondheidscheck. nl/wat-is-de-gezondheidscheck/. Geraadpleegd op: 28 mrt 2018.

4. Venkatesh V, Thong JY, Xu X. Consumer acceptance and use of information technology: extending the unified theory of acceptance and use of technology. MIS Q. 2012;36(1):157-78.

5. Centraal Bureau voor de Statistiek. StatLine Gezondheid, leefstijl en zorggebruik 2000-2009 - zelfgerapporteerde leefstijl. Den Haag/Heerlen: CBS. 2018. http://statline.cbs. $\mathrm{nl} /$ Statweb/. Geraadpleegd op: $28 \mathrm{mrt} 2018$.

6. Alssema M, Newson RS, BakkerSJ, etal. Oneriskassessment tool for cardiovascular disease, type 2 diabetes, and chronic kidney disease. Diabetes Care. 2012;35(4):741-8.

7. Conroy RM, Pyörälä K, Fitzgerald AP, et al. Estimation of ten-year risk of fatal cardiovascular disease in Europe: the SCORE project. Eur Heart J. 2003;24(11):987-1003.

8. GGD Hart voor Brabant, GGD West-Brabant. Brabantscan, 2016. https://brabantscan.nl/. Geraadpleegd op: $29 \mathrm{mrt}$ 2018.

9. Centraal Bureau voor de Statistiek. StatLine Bevolking; onderwijsniveau. Den Haag/Heerlen: CBS. 2018. http:// statline.cbs.nl/Statweb/. Geraadpleegd op: 6 nov 2018.

10. Kroneman MW, Verheij R. De griepprikin Nederland: motivatie voor deelname en distributiekanalen. Utrecht: NIVEL; 2003.

11. Groenenberg I, Crone MR, Dijk S van, et al. Response and participation of underserved populations after a three-step invitation strategy for a cardiometabolic health check. BMC Public Health. 2015;01(3):15-854.

12. CZ. Coaching op Leefstijl-programma (CooL) bewezen effectief en in 2019 vergoed uit de basisverzekering. 2017. https://www.cz.nl/over-cz/nieuws/2017/coaching-opleefstijl-programma-bewezen-effectief. Geraadpleegd op: $14 \operatorname{dec} 2017$

13. Luiten A. Benaderingsstrategieën: responsverhogende maatregelen bij sociale statistieken. Den Haag, Heerlen: CBS; 2009.

14. Sørensen K, Pelikan JM, Röthlin F, et al. Health literacy in Europe: comparative results of the European healthliteracy survey (HLS-EU). Eur J Public Health. 2015;25(6):1053-8. 